\title{
THE SEA LEVEL CHANGE OF THE TROPICAL PACIFIC AND THE ROTATION OF THE EARTH
}

\author{
DAWEI ZHENG and GANG CHEN \\ Shanghai Observatory, Chinese Academy of Sciences \\ Shanghai 200030, P.R.CHINA
}

\begin{abstract}
About 30-year time series of the length of day (LOD) and the Pacific sea level are analysed in the paper. The close correlation between Earth rotation and sea level is discussed. Dynamical analysis of the angular momentum of tropical Pacific Ocean and solid Earth shows that the sea level changes of eastern and western Pacific lead the LOD interannual change in phases of 1 and 2 months respectively. The tropical Pacific effect accounts for about 31\% in LOD change and is even more evident during El Nino events. Changes of the Earth rotation also cause changes in the oceanic mass distribution.
\end{abstract}

\section{INTRODUCTION}

Modern geodetic and atmospheric observations have proved that the changes in the length of day (LOD) are strongly coupled with the changes in the atmospheric angular momentum (AAM) at the periods from subseasonal to interannual time scales [Rosen et al., 1990]. Recent papers have shown that the AAM changes constitute more than $90 \%$ of the changes in LOD at the annual period but rather less at interannual time scales[Eubanks et al., 1986; Zheng, 1988]. To understand the interannual change in the Earth rotation better, researchers are now likely to pay more attention to the ocean, which was neglected before [Song, et al., 1989].

Because of the shortage of oceanic observation data, the study of the effect of ocean on Earth rotation has been limited to theoretical discussions and model analysis [Peltier, 1988]. In Section 2, we analyse the Pacific sea level data from the TOGA Sea Level Center and the LOD data. Section 3 and Section 4 describe the relation between Earth rotation and sea level change in the tropical Pacific $\left(20^{\circ} \mathrm{N}-20^{\circ} \mathrm{S}\right)$ and the effect of oceanic angular momentum (OAM) on the LOD.

\section{DATA AND DATA PROCESSING}

The main source of the LOD time series is the UT1-UTC data of the International Earth Rotation Service (IERS) from 1962 to 1990. After correcting the zonal harmonic tide effects using the theoretical results, we have got the LOD data at 5-day intervals. The Multi-Stage Filter [Zheng, et al., 1992] is used to eliminate components with periods which are longer 
than 10 years. The monthly values are calculated via a simple month average . Finally the monthly mean values of LOD are computed by departure method to remove average seasonal variation in LOD data series. The results are plotted in Fig.1 which shows the interannual variation of LOD.

The sea level information was provided by the International TOGA Sea Level Center with its sea level network distributed in the Pacific $\left(100^{\circ} \mathrm{E}-70^{\circ} \mathrm{W}, 40^{\circ} \mathrm{N}-40^{\circ} \mathrm{S}\right)$. The networks consist of 87 tide guage stations operated in 1962-1990(Fig.2). Becanse some stations have one more observational series in different time, there are altogether 94 strictly quality controlled montlily data series, which include 55 stations and 60 data series in tropical belt of Pacific $\left(20^{\circ} \mathrm{N}-20^{\circ} \mathrm{S}\right)$ [Caldwell, et al., 1989].

To compute the average sea level, at first, the strictly check and adjustment are applied to the data series at each tide guage station to calculate the relative sea level. Then the method of departure is used to remove the mean seasonal variation in the sea level data. Finally, we use the method of subarea average, and linear interpolation to fill the space gaps where there is no tide guage station for which the mean sea level values are obtained.

Analysis of the long time scale variations of mean Pacific sea level based on 87 ticle guage stations by means of the unweighted least square method indicates that the sea level is apparently rising at an averaged rate of about $1.79 \pm .01$ millimeter per year from 1962 through 1990 (Fig. 3).

\section{THE CHANGES OF EQUATORIAL PACIFIC SEA LEVEL AND LOD}

The differences between eastern and western equatorial Pacific rolative sea levels are presented in Fig. 4. The mean sea level change of the eastern equatorial Pacific (SLCE) is ob)tained from 7 tide guage station olservations in the field $\left(140^{\circ} \mathrm{W}-80^{\circ} \mathrm{W}, 10^{\circ} \mathrm{N}-10^{\circ} \mathrm{S}\right.$ ) ( solid line), and the mean sea level change of the western equatorial Pacific (SLCW) is calculated from 24 tide guage station observations in the area $\left(100^{\circ} \mathrm{E}-170^{\circ} \mathrm{E}, 10^{\circ} \mathrm{N}-10^{\circ} \mathrm{S}\right)($ dashed line). The two data series have been obtained by 5-point moving average processing.

It is evident that the SLCE has an opposite phase change from the SLC.W. The maximum difference of the peaks between them during the 1982-1983 El Nino event was nearly 40 cm. There are evidently large scale water flows between the eastern and western equatorial Pacific as mentioned by Wyrtki [1984].

It can be seen by comparing Fig. 4 and Fig. 1 that the LOD variation data from astronomical observations correspond well to those of the SLCE and the SLCW. The interannual rate of Earth rotation is accelerating when the western equatorial Pacific sea level rises and the eastorn equatorial Pacific drops, while the interannual Earth rotation is decelorating when the sea level drops in the western equatorial Pacific and rises in the eastern equatorial Pacific. It is shown from cross correlation results of the LOD variation with SLCE and SLC.W that the phases of the sea level changes in the eastern and western Pacific lead that of the interannual LOD change by about 1 and 2 months respectively. Thus besicles atmosphere circulation, the water exchange of the equatorial Pacific may be also one of the important excitation factors canse the LOD fluctuations.

\section{ANGULAR MOMENTUM EXCHANGE BETWEEN THE SOLID EARTH AND THE TROPICAL OCEAN}


Since the atmosphere, ocean and solid Earth are taken to form a closed system, this system should conserve its total angular momentum in the absence of external torques. Any changes of the ocean angular momentum will be compansated by changes in another part of the Earth. So the change of total angular momentum should satisfy the following formula.

$$
\delta M_{\text {shell }}+\delta M_{\text {ocean }}+\delta M_{\text {other }}=0
$$

where $\delta M_{\text {shell }}, \delta M_{\text {ocean }}$ and $\delta M_{\text {other }}$ are the angular momentum variations of shell, ocean and other part of Earth respectively.

The large scale ocean structure can be divided into two layers. Changes of sea level height $\triangle \mathrm{L}$ relate directly to changes of isotherm depth $\triangle \mathrm{D}$ [Wyrtki, 1985]. According to a close relation between $\triangle \mathrm{L}$ and $\triangle \mathrm{D}$ [Wyrtki 1985], the change of the upper layer volume can be calculated from the sea level change as:

$$
H=(\rho / \Delta \rho) \iint \Delta L a^{2} \cos \varphi d \varphi d \lambda
$$

where $\rho / \Delta \rho$ is the relative density difference between the two layers with a value $\rho / \Delta \rho=$ $5 \times 10^{-3}$ [Wyrtki,1985] and $\mathrm{a}$ is the equatorial radius of the earth with a value $6378 \mathrm{~km}, \varphi$ and $\lambda$ are the latitude and longitude, respectively.

Following (2), the upper volumes of the eastern and western tropical Pacific $\left(20^{\circ} \mathrm{N}\right.$ $20^{\circ} \mathrm{S}$ ) are computed as $\mathrm{H}_{e}$ and $\mathrm{H}_{w}$ respectively. Then the average rate of the eastward water movement of the upper layer can be derived from the difference of upper volumes $H_{c} w=$ $\mathrm{H}_{\epsilon}-\mathrm{H}_{w}$ during the time $\Delta \mathrm{t}$. We assume a homogeneous ocean of approximately constant depth without change of density and salt. After some manipulation, the oceanic angular momentum change $\delta \mathrm{M}_{\text {ocean }}$ can be approximated as

$$
\delta I_{o c \epsilon a n} \doteq \frac{\rho a^{2} H_{e w}\left(\lambda_{2}-\lambda_{1}\right)}{4 \Delta t}\left(\frac{1}{2}+\frac{\sin 2 \varphi_{2}-\sin 2 \varphi_{1}}{4\left(\varphi_{2}-\varphi_{1}\right)}\right)
$$

where, $\rho$ is the ocean density as $1027.675 \mathrm{kgm}^{-3}$. The integrated domain is bounded along longitudes $\lambda_{1} ; \lambda_{2}$, and latitudes $\varphi_{1}, \varphi_{1}$. With the coefficient of $1.668 \times 10^{29} \mathrm{~s}^{2} / \mathrm{kgm}^{2}$, the change of OAM corresponds to $\mathrm{LOD}_{\text {ocean }}$ variation as shown in Fig. 5.

We can observe the ocean effect in LOD change more clearly from the contribution of OAM [Fig. 5]. It should be noted that the peaks of $\mathrm{LOD}_{\text {ocean }}$ variation are consistent with the $\mathrm{LOD}_{\text {earth }}$ variation, especially during the $\mathrm{El}$ Nino events, while the $\mathrm{LOD}_{\text {ocean }}$ sometimes slightly leads the LOD $_{\text {earth }}$. It is suggested that the ocean is also one of significant excitation sources in interannual change of the Earth rotation besides the atmosphere.

The amplitude of the interannual LOD $_{\text {ocean }}$ variation is below $0.1 \mathrm{~ms}$ in general. The average value from 1973 through 1989 is $0.045 \mathrm{~ms}$, about $31 \%$ of the variation in LOD, arth, but the highest peak is over $0.2 \mathrm{~ms}$ during the strong 1982-1983 El Nino event. The ocean effect on the interannual change of LOD is not negligible. Especially during the El Nino events, the anomaly of the tropical Pacific water movement has more significant effects on Earth rotation.

The total upper volume of the tropical Pacific area is estimated by adding the eastern and western upper water volumes as $\mathrm{H}=\mathrm{H}_{\epsilon}+\mathrm{H}_{w}$ and is shown in Fig. 6. Comparing with the LOD variation (Fig.1), we find that the interannual LOD is in opposite phase with $\mathrm{H}$, and the acceleration and deceleration of interannual Earth rotation might induce mass increase and decrease of the tropical Pacific in order to conserve the total angular 
momentum. The cross-correlation estimate shows the maximum correlation coefficient is -0.61 and the LOD leads $H$ by about 5 months. This suggests that the interannual change of Earth rotation interacts with the change of the tropical Pacific.

\section{CONCLUSIONS}

Dynamics and data analyses of LOD and sea level variations suggest the following conclusions :

A. There is significant correspondence between the sea level and the interannual Earth rotation. Their interaction becomes more obvious during the El Nino events. The anomalous movements of the Pacific water with eastward or westward flow cause the deceleration and acceleration of the interannual Earth rotation.

B. The approximate oceanic angular momentum budget shows that the OAM contributes the variation of the Earth angular momentum and accounts for abont 31\% of the interannual variation of the LOD. The contribution becomes much larger during the El Nino events.

C. The interannual change of Earth rotation causes oceanic mass distribution.

Acknowledgments. We wish to thank Prof. Klaus Wyrtki, university of Hawaii, and the Sea Level Center of the International TOGA Project for providing us with the sea level data sets. We are also very grateful to Drs. Chopo Ma, Paquet and McCarthy for their kind discussions. The research reported here is supported by the National Key Basic Scientific Research Project and by the National Natural Science Foundation of China.

\section{REFERENCES}

1. Caldwell, P. et al.(1989), 'TOGA Sea Level Center: data from the Pacific', JIMAR, No.89 - 202, 34pp.

2. Eubanks,T.M., Steppe,J.A. and Dickey,J.O.(1986), 'The El Nino, the sonthern oscillation and the Earth rotation', in Earth Rotation: Solved and Unsolved Problems, D.Reidel Publishing Company.

3. Peltier,W.R.(1988), 'Global sea level and earth roattion', Science, 240,895-901.

4. Song,G.X., Zheng,D.W. and Luo, S. F.(1989), 'The dynamical analysis of Earth rotation in connection with ENSO', Acta Astronomic Sinica, 30, 310-314.

5. Rosen,R.D., Salstein,P.A and Wood,T.M.(1990), 'Discrepancies in the earthatmosphere angular momentum builget', J. Geophys. Res.,95, 265-279.

6. Wyrtki,K.(1984), 'The slope of sea level along the equator during the 1982-1983 El Nino', J.Geophys.Res. 89, 10419-10424.

7. Wyrtki,K.(1985), 'Water displacements in the Pacific and the genesis of El Nino cycles', J.Geophys.Res., 90, 7129-7132.

8. Zheng,D.W.(1988), 'Earth rotation and the activities of ocean and atmosphere', Advance in Astrnomy, 6, 316-328.

9. Zheng,D.W. and Luo,S.F.(1992), 'Contribution of time series analysis to data processing of astronomical observation in China', Statistica Sinica, 2, 605-618. 


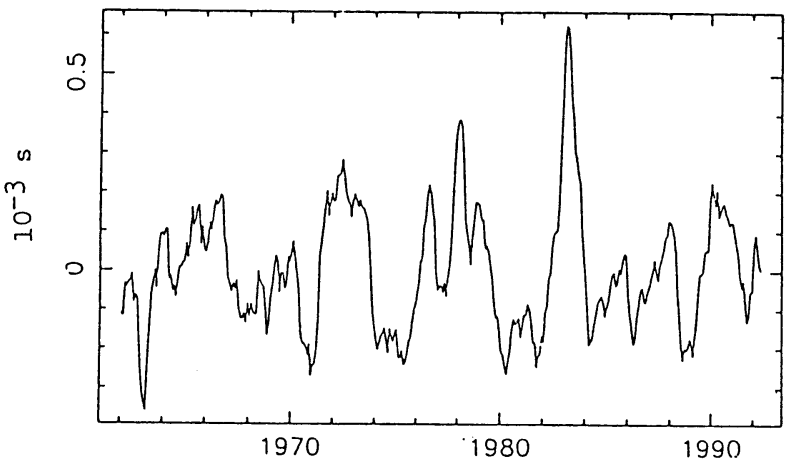

Figure 1. The interannual change of LOD from IERS during 1962 through 1990.

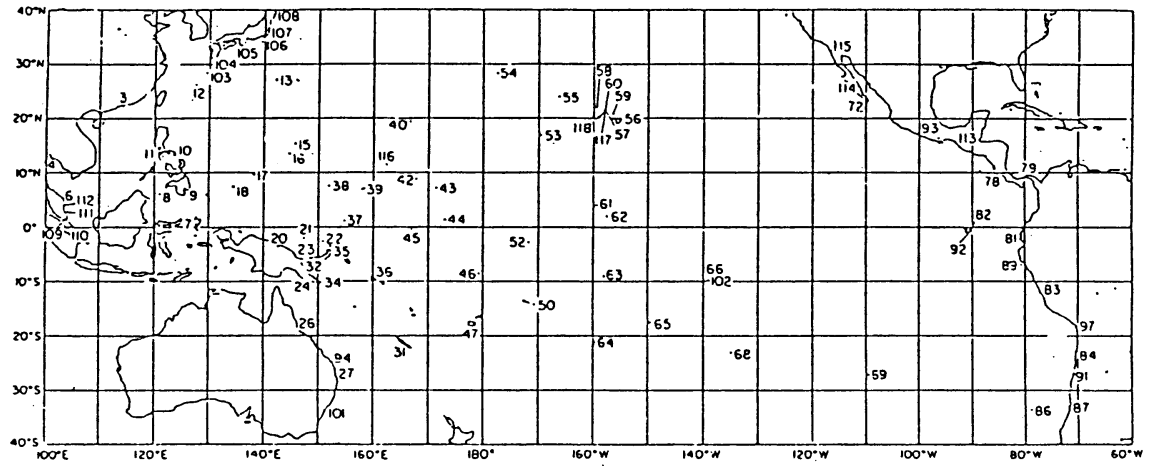

Figure 2. The network distribution of 87 tide guage stations in the Pacific provided by the Sea Level Center.

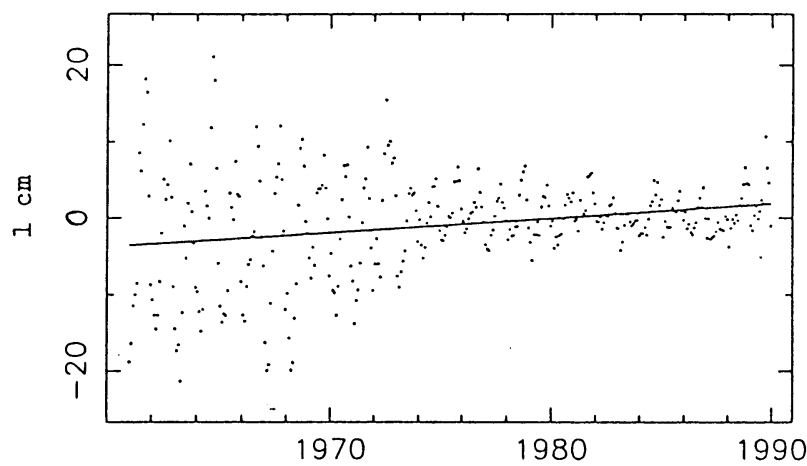

Figure 3. The mean sea level change in the Pacific (points) and the sea level rising (line) at an averaged rate of about $1.79 \pm 0.01 \mathrm{~mm} / \mathrm{yr}$. during 1962 through 1990. 


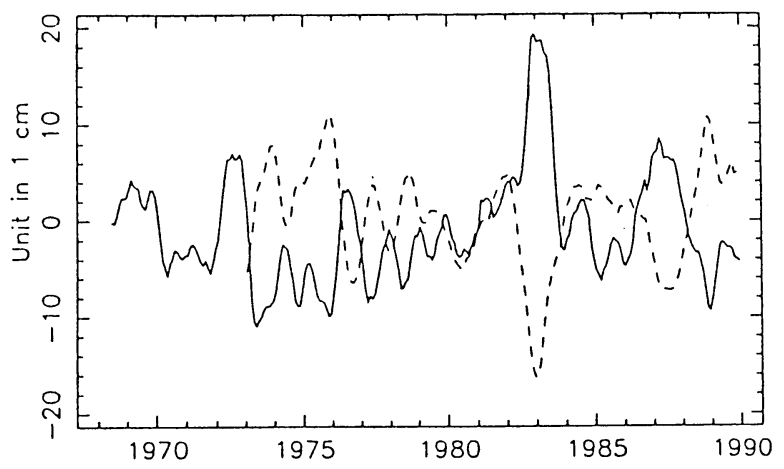

Figure 4. The different regularity between eastern (solid curve) and western (dashed curve) equatorial Pacific sea level changes.

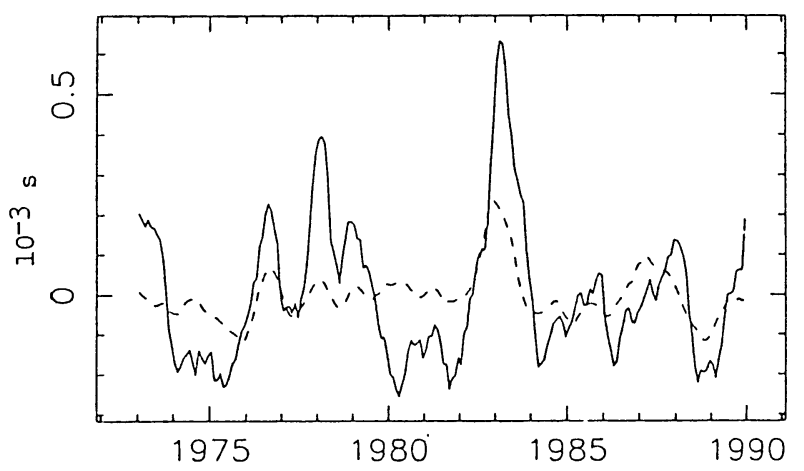

Figure 5. The interannual LOD (solid curve) and oceanic LOD (dashed curve) derived by the change of oceanic angular momentum in tropical Pacific.

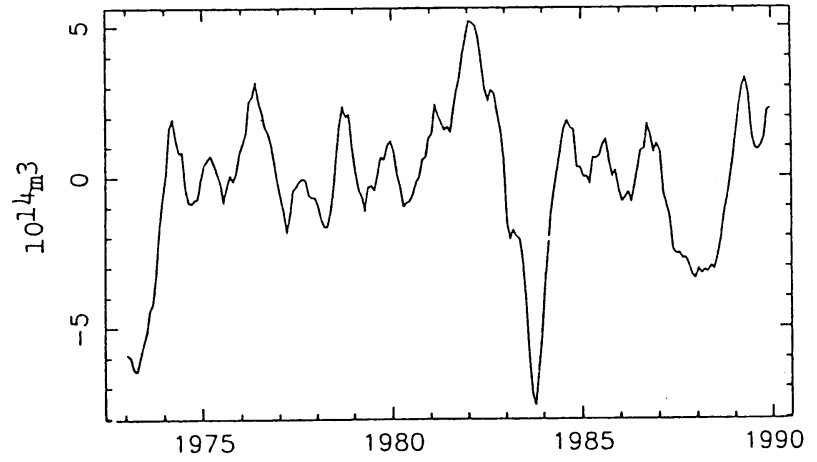

Figure 6. The change of the total upper water volume in tropical Pacific calculated by synthesizing the eastern and western upper water volumes. 